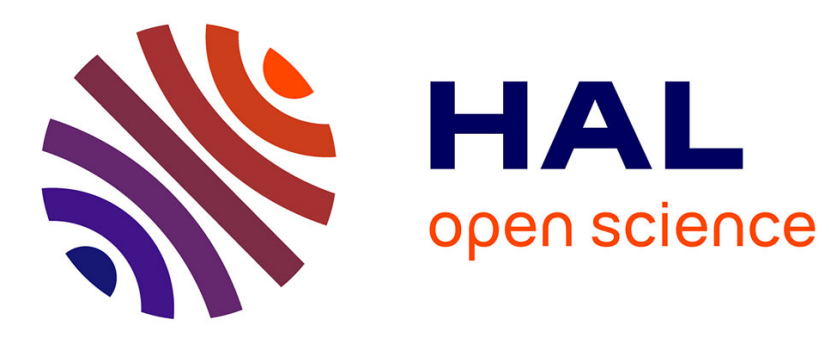

\title{
Assessing visual survey protocols to capture brand-related emotional insights
}

Stéphane Ganassali, Justyna Matysiewicz

\section{To cite this version:}

Stéphane Ganassali, Justyna Matysiewicz. Assessing visual survey protocols to capture brand-related emotional insights. Qualitative Market Research: An International Journal, 2018, 21 (1), pp.2-17. 10.1108/QMR-09-2016-0080 . hal-01702045

\section{HAL Id: hal-01702045 \\ https://hal.univ-smb.fr/hal-01702045}

Submitted on 6 Feb 2018

HAL is a multi-disciplinary open access archive for the deposit and dissemination of scientific research documents, whether they are published or not. The documents may come from teaching and research institutions in France or abroad, or from public or private research centers.
L'archive ouverte pluridisciplinaire HAL, est destinée au dépôt et à la diffusion de documents scientifiques de niveau recherche, publiés ou non, émanant des établissements d'enseignement et de recherche français ou étrangers, des laboratoires publics ou privés. 


\title{
Assessing visual survey protocols to capture brand-related emotional insights
}

\author{
Stéphane Ganassali \\ IREGE, University of Savoie Mont-Blanc, Annecy le Vieux, France, and \\ Justyna Matysiewicz \\ Department of Consumption Research, University of Economics in Katowice, \\ Katowice, Poland
}

\begin{abstract}
Purpose - This paper aims to present the assessment of different self-reported approaches that can be used to identify and measure consumers' emotional responses towards brands. The goal is to determine whether visual and spontaneous protocols are able to generate deeper insights than only closed groups of scales, and to consider pictorial tools as innovative and challenging measurement techniques for brand value assessment.

Design/methodology/approach - Three versions of the same consumer online survey dedicated to identifying some brand-related consumer emotional insights were created to be compared in terms of quality of responses, interviewees' evaluation and richness of insights.

Findings - Visual protocols provide more specific emotional responses and are considered as useful for "capturing deep contextual meanings of consumer experience". They clearly provide deeper insights and better emotional granularity. It can be generally concluded that different emotions' self-report measurements are adapted to some diverse research questions or situations.

Research limitations/implications - This paper is based on research with a limited number of participants. It focuses on the use and consumer emotional insights delivered by three tested protocols rather than detailed analysis of the specific profiles of consumers.

Practical implications - The authors provide some recommendations of different research techniques, which can be used to identify and measure consumers' emotional reactions towards brands.

Social implications - Their paper encourages a critical reflection about research methods that are deployed for marketing and consumer behaviour purposes. Their work promotes a hybrid and not dogmatic approach, centred around the perception and motivation of the respondents more than on the expectations of the researcher only.

Originality/value - Research outcomes among different self-reported protocols using internet technologies are compared. Quality of responses and richness of insights are measured in a quite innovative and comprehensive way. The paper also gives detailed recommendations to researchers interested in consumers' emotional reactions towards brands measurements.
\end{abstract}

Keywords Emotions, Brand attachment, Visual methods, Mixed methods, Collage,

Quality of responses

\section{Introduction and review of literature}

Within a general context in which experiential aspects of consumption are considered as crucial (Holbrook and Hirschman, 1982), various strong feelings can be observed in a

The authors would like to acknowledge European Master in Business Studies students for their participation in the experiment and Sphinx Company for technological support. 
consumer-brand relationship (CBR). Consumers can have a passion for the brand or hate it. Love is one of those strong feelings that marketers try to create between their brands and consumers (Albert et al., 2008). Once customers turn into brand lovers, it is difficult for competitors to attract those loyal followers. They may also become the ambassadors of the brand and try sometimes to "evangelize" around them. At that point, emotional and experiential consumer insights become more important and crucial for marketing decisionmakers ( $\mathrm{Ng}$ and Hort, 2015), especially in some areas or sectors in which those aspects are very central, such as brand strategy, but also tourism, culture, entertainment or retailing. However, for certain consumers, brand-related emotions are difficult to capture (Derbaix and Poncin, 2005; Thomson et al., 2005). Within the typology of affective reactions (Derbaix and Pham, 1991), we consider brand-related "emotions" and "feelings", as the stimulus is specific (the brand) and the somatic intensity is moderate to strong. For emotions, the duration is brief, while for feelings it is moderate to long.

The aim of this study is therefore to evaluate some different instruments to capture brand-related consumer emotional insights designed under different approaches. There is a growing trend of promoting the joint adoption of both verbal and non-verbal approaches for better assessing emotional responses and providing additional or deeper insights regarding associations made by consumers about brands on large scale. Within a global context of a rising "image culture" (Jansson, 2002), we tried to consider more illustrated and spontaneous instruments using pictures or collages and test them within an international environment.

\section{Theoretical background}

Methods of assessing emotions

There are commonly three components of emotions: cognitive, physiological and behavioural (Gil, 2009). Our research is focused on an understanding of the cognitive dimensions. Methods of assessing emotions can be generally divided according to the components of the emotional response as follows:

- affective self-reports, including verbal self-report, visual self-report (Bradley and Lang, 1994) and moment-to-moment rating (Poels and Dewitte, 2006);

- physiological measurements (e.g. skin conductance, pupillary responses and pulse rate); and

- behavioural changes (e.g. facial action coding system, e.g. Ekman et al., 1980; Kaiser and Wehrle, 2001; Förster, 2014; Kim et al., 2015).

Physiological and behavioural measurements are difficult to use for a large sample and in a brand context based on several factors. First, physiological measurements allow detecting the occurrence of even mild emotions, but they cover the specific emotion attached to the brand. Second, the measurement of behavioural changes, e.g. by using facial action coding systems, does not yet consider marketing specific emotions. Those autonomic measurements are well-adapted to advertisement testing, for example (Droulers and Lajante, 2015), when the stimulus is precise and temporized. However, brand-related emotions elicit more durable emotional states, and they could benefit from a more qualitative assessment, not just intensity or valence. Thus, we have determined that the cognitive methodology of self-reports is the most appropriate way to measure brand-related affective reactions. Selfreporting gauges subjective feelings requiring respondents to report them with the use of set rating scales or verbal protocols (Förster, 2014). We will assess some of these based on their ability to provide good-quality consumer answers and insights. 


\section{The power of pictures}

More specifically, we consider protocols using pictures to properly capture consumers' emotional responses towards brands. The theory of "dual-coding" presupposes the primacy of images to capture the most emotional non-verbal reactions (Paivio, 1971). According to Harper (2002), the introduction of visual material in the interview gives access to "other parts of the human consciousness". Visual methods also tend to generate not only more but also an entirely different kind of data than those resulting from a purely verbal interview (Harper, 2002; Warren, 2002). This has a physical basis: the parts of the brain that process visual information are evolutionarily older than the parts that process verbal information. Thus, images evoke deeper elements of human consciousness than do words, whereas exchanges based on words alone use less of the brain's capacity than do exchanges in which the brain is processing images and words (Harper, 2002). As explained by Anastas (1994), visuals initiate respondents' imagination and verbal responsiveness. When asked a question such as "What are your feelings when you use this product?", some consumers become tense and anxious because they seldom have the opportunity to express feelings about anything, let alone a commonplace product. When asked, "Select a picture and describe how it shows your feelings when you use the product", they tend to relax and launch into complex stories (Anastas, 1994).

Scott and Vargas (2007) consider that pictures (in commercial communication) are beginning to function "in a manner analogous to a writing system". Then it would be possible to communicate brand information in a predictable way, sometimes more effectively, with pictures than with alphabetic writing. The basis for what Scott and Vargas refer to as "writing-with-pictures" is located in the contemporary diffusion of mass media, which makes it possible to learn picture meanings in a way that was not feasible in earlier eras. Scott (1994) sees a convention-based system in which "viewers and makers share certain expectations, schemata, and implicit rules".

Methods of collecting images (known as "collages") for capturing consumer behaviours and attitudes have recently attracted increasing levels of interest. The Zaltman metaphor elicitation technique method (Zaltman, 1997), which has been popular for decades, invites respondents to produce a composition using several chosen images to express their point of view on the theme being studied. The selected images lead to a discussion with an analyst, who records and interprets the explanations given by the respondent in accordance with a clearly defined procedure (Zaltman and Coulter, 1995). The "photo-language" technique is also quite well-known in the social sciences. Such techniques involve asking participants (in a group or individually) to express themselves in relation to a collection of images prepared by the researchers, for example, teenagers on the topic of sexuality (Baptiste et al., 1991). Another example is the "album on line" (AOL) method (Vernette, 2007) in which following individual reflection on a given scenario, participants agree on a selected "album" of images (obtained online) to express their representations of the theme being studied. Keywords and brief narratives are also generated. On this basis, the AOL protocol has been clearly designed for capturing consumption experiential contents.

The use of pictures as a means of expression for emotional reactions is sometimes considered as less biased than verbal instruments (Derbaix and Filser, 2011), which was recently discussed and validated through research by Yoon et al. (2013). In the field of design studies, they used pictures to facilitate "emotional granularity" for a finer and deeper expression of emotional reactions. Some recent research projects have begun to investigate the efficiency of such protocols such as the "online multi-image elicitation" (OMIE) (Ganassali, 2016) or the "quali-quant synaesthesia" (Pawle and Delfaud, 2014), for example. In the field of brand image management, the use of pictures has provided helpful insights in 
many research problems, such as recently to explain brand meaning gaps and dynamics (Wilson et al., 2014).

\section{Mixed-methods}

Parallel to the use of pictures, researchers need to consider some new "mixed" protocols (Spanjaard et al., 2014) to combine the interests of both qualitative techniques (spontaneity and depth of analysis) and quantitative techniques (volume and objectification). There is a clear and recent growing trend of interest in mixed methods in the social sciences (Tashakkori and Teddlie, 2010) to bridge the traditional gap between extreme positivist and interpretivist approaches. More specifically, it is envisaged to develop a number of electronic versions of traditional qualitative visual methods (e.g. collages), to update them (Koller and Sinitsa, 2009) and take advantage of the power of dissemination of the internet.

The general concept is to keep the natural advantages of classic qualitative techniques like depth and subtlety of analysis while increasing the number of observations possible because of available multimedia internet protocols. This would result in a more significant number of answers, which allows the researcher to analyse and discuss the observed outcomes on a more objective basis.

Those mixed protocols, some of which are presented later in this paper, are also based on images collected from the internet and are then shown to respondents as part of an online survey, which is comparable to a more recent methodological approach described as "digital visual anthropology" (Pink, 2011). It is important to draw a connection between this type of method and the rise in certain contemporary Western societies of what some authors have called the "image culture". In this culture, media images (e.g. via Facebook, Instagram or Snapchat) are being increasingly used as sources and expressions of cultural identity (Jansson, 2002) and are a reflection - or indeed the object - of several modern consumer phenomena, especially for teenagers and young adults.

\section{Objectives and methodology of the study}

Our objective is to compare certain traditional closed scales, in which a list of items is proposed and evaluated through Likert measurements, to other more illustrated and spontaneous self-report instruments using pictures or collages. We want to determine whether visual and spontaneous protocols are able to generate better and deeper insights than the groups of verbal scales only.

\section{Criteria to assess the quality of responses}

According to the possible consequences of satisficing responding behaviours (Krosnick, 2000), we consider the response and completion rates (Ganassali, 2008). We also are interested in the evaluation of the instrument by the respondent, in their capacities of favouring the respondent's ability and motivation and to reduce the task difficulty. Then, we can obtain a double assessment of satisficing behaviours and the related quality of responses: a declarative one via the final evaluative questions and a factual one through the actual response behaviours. Additionally, we can also consider the "evocative richness" of responses, which measures the volume of relevant emotional contents formulated by the respondents in their reactions. For example, via a systematic content analysis, it is possible (Mossholder et al., 1995) to quantify the number of experiential or emotional insights included in the textual responses to the open-ended questions of the survey. 


\section{Methodology: visual and scales protocols}

We have designed three versions of the same consumer survey dedicated to identifying a number of brand-related consumer emotional insights. The three survey protocols share the same introductory stage - in which respondents are asked to state their current favourite brand, the same final section dedicated to the evaluation of the survey (ability, motivation and task difficulty) and some socio-demographics. The first protocol is simply based on the emotional attachment scale developed by Thomson et al. (2005) and comprised ten items evaluated through a Likert scale that can be defined as "assisted declarative". Likert scales are currently and by far the dominant measuring instruments for quantitative studies about CBRs[1]. The second is "assisted associative" and consists of an OMIE elaborated according to the principles defined by Ganassali (2016). The respondents are asked to first choose three pictures to describe - in that case - their feelings towards their favourite brand[2]. In the next screen, the three chosen pictures are presented again, and respondents are asked to explain why they chose them and what they represent. It was proved that those kinds of mixed protocols were promising as a means to stimulate the abundance and diversity of responses in consumer behaviour studies. The third scenario is "spontaneous associative", and, like a collage, the consumer can choose the pictures they want to express their feelings. This is referred to as the "on-line collage" and originates from the results of some first experiments (AOL, for example - Vernette, 2007) combining the advantages of several existing techniques. In the AOL process, participants extract keywords from stories associated with the studied experience and select representative images on the internet. A collective album is subsequently created by a moderator or by a process of collective selection. In the on-line collage protocol, respondents are requested to search for pictures on the internet and upload them on the survey questionnaire as an individual expression of their emotions towards any relationship with a brand or consumer experience. Of course, those three protocols do not exactly follow the same objective. The Likert scales are supposed to be used for confirmatory research, while the visual protocols (especially n ${ }^{\circ}$ ) are more exploratory by nature.

\section{The three tested protocols}

The following screen shots comprising Figure 1 illustrate the three protocols and the way they are concretely presented to the survey target respondents.

\section{Sample}

For that methodological piece of research, we used a convenience sample. In November 2015, the surveys were first circulated amongst two groups of bachelor and master degree students in two countries: France and Poland. They were also distributed to a panel of company managers in France to obtain a larger variety of profiles in terms of age groups. The three versions of the survey were randomly assigned to target contacts. In total, we received 532 responses. The average age of the respondents was 31 years. The sample was composed of 60 per cent of female respondents, and the level of education was high with on average between three and four years of higher education.

\section{Findings and results}

We begin introducing the results with behavioural and factual measurements and then look at the evaluation of the respondents. Finally, we consider the very challenging evocative richness of the protocols. 
Figure 1. Screenshots of the three different tested protocols

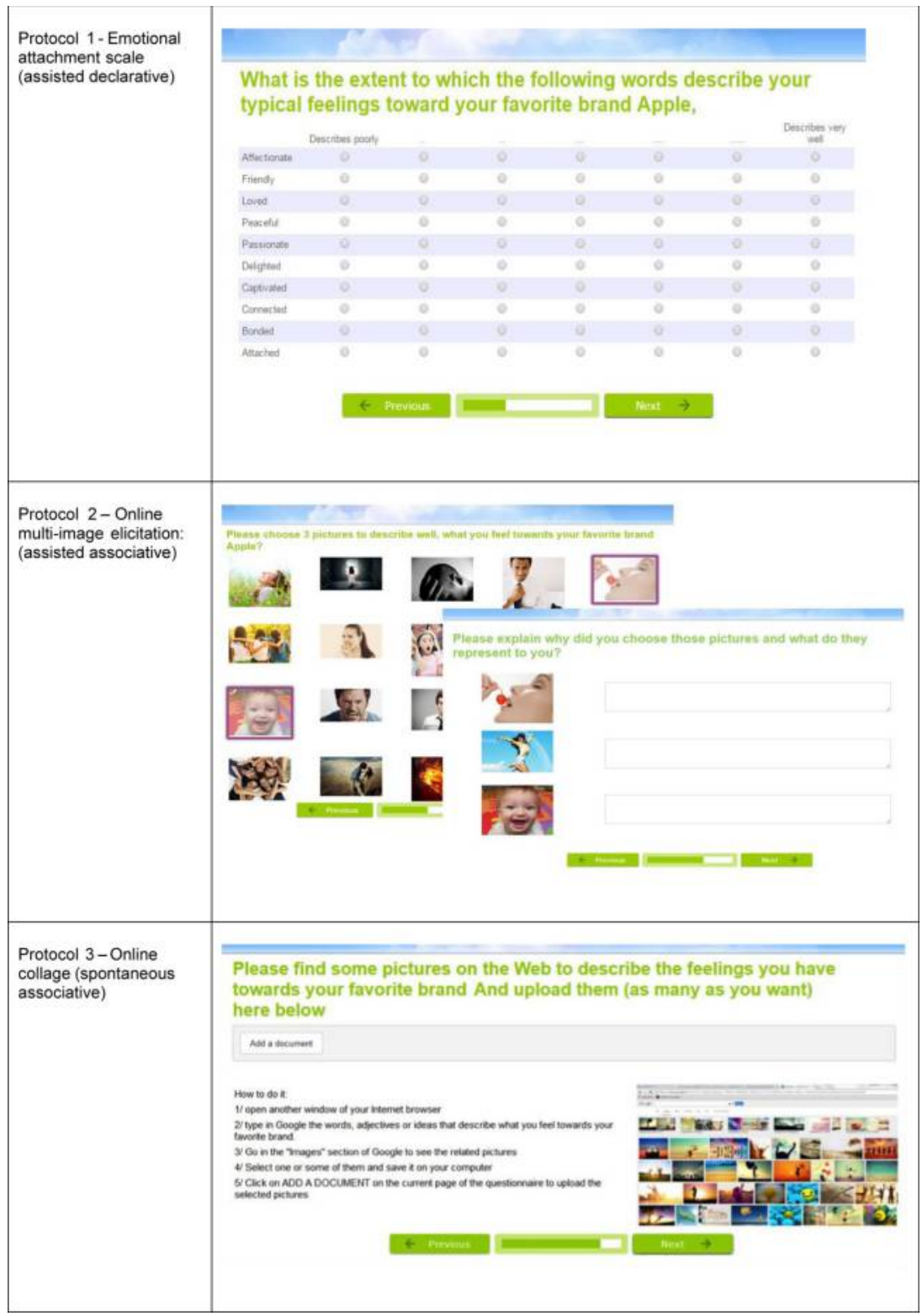

Dropouts, time and completion rates

As can be seen from Table I, the dropout rates are similar for Protocols 1 and 2 (between 5 and 6 per cent) but higher for Protocol 3, which reaches to almost 20 per cent. The completion times for the three different protocols are difficult to compare because the tasks 
are quite different. It takes naturally much longer to browse the internet and upload some significant pictures so the survey with the third protocol takes almost $10 \mathrm{~min}$ on average. The first two protocols result in a shorter survey: almost 6 min for the OMIE and 5 min for the first protocol proposing scales.

For the completion rate, we are interested in the proportion of missing values in the various situations considering that only the very first question related to the favourite brand is programmed as mandatory and cannot be skipped. The highest completion rate is obtained for the OMIE protocol: more than 91 per cent of the respondents completed the full task by choosing two pictures and justifying their choices with free text inputs. For Protocol 1, 87 per cent of the participants completed all ten scales. Finally, only 82 per cent of the respondents uploaded one or more pictures for Protocol 3 and justified their choices with free text inputs. On average, respondents uploaded two or three pictures.

\section{Ability, motivation and task difficulty}

As the likelihood to satisfice (and then to answer in an inaccurate way) is linked to respondent ability, respondent motivation and task difficulty (Krosnick, 2000), we also compare the perception of the respondents on those dimensions for the three different protocols. At the end of the survey, respondents were asked to assess the questionnaire with eight related questions and an OMIE. As we can see from Table II, Protocol 1 (the emotional attachment scale) is considered as easy and quick but not very interesting and enjoyable. In addition to that, its score for expressiveness is low. Protocol 2, OMIE is well evaluated: quite easy and quick, exciting, enjoyable and helpful for the expression of feelings. Protocol 3 (the online collage) is rated higher for feelings expressiveness and lower for quickness and easiness.

Table I.

Dropout, completion rates and completion time for the three tested protocols

\begin{tabular}{lccc}
\hline & $\begin{array}{c}\text { Dropout } \\
\text { rate }(\%)\end{array}$ & $\begin{array}{c}\text { Average completion time } \\
(\text { excl. 5\% lower and higher) }\end{array}$ & Protocol completion rate (\%) \\
\hline P1 (emotional attachment scale) & 5,7 & $4 \mathrm{~m} \mathrm{58 \textrm {s }}$ & 87,2 \\
P2 (OMIE) & 5,4 & $5 \mathrm{~m} \mathrm{48 \textrm {s }}$ \\
P3 (online collage) & $19,8(*)$ & $9 \mathrm{~m} \mathrm{25 \textrm {s }}$ & 91,4 \\
& & $82,3(* *)$
\end{tabular}

Notes: *Significantly different from P1 and P2 at $p<0.05 ;{ }^{* *}$ significantly different from P2 at $p<0.05$ (Exact Fisher tests)

\begin{tabular}{lcccl}
\hline Protocols & $\begin{array}{c}\text { P1 (emotional } \\
\text { attachment scale) }\end{array}$ & $\begin{array}{c}\mathrm{P} 2 \\
\text { (OMIE) }\end{array}$ & $\begin{array}{c}\text { P3 (online } \\
\text { collage) }\end{array}$ & $\begin{array}{l}\text { Significant difference at } \\
p<0.05 \text { (t test) }\end{array}$ \\
\hline It is well-designed & 3,71 & 3,99 & 3,76 & None \\
It helped me to express my feelings & 2,76 & 3,27 & 3,35 & $\mathrm{P} 1 \neq \mathrm{P} 2$ and $\mathrm{P} 1 \neq \mathrm{P} 3$ \\
It motivated me to answer & 3,31 & 3,71 & 3,18 & $\mathrm{P} 1 \neq \mathrm{P} 2$ and $\mathrm{P} 2 \neq \mathrm{P} 3$ \\
It was easy to use & 4,89 & 4,97 & 3,72 & $\mathrm{P} 1 \neq \mathrm{P} 3$ and $\mathrm{P} 2 \neq \mathrm{P} 3$ \\
It was easy to answer & 4,55 & 4,65 & 3,73 & $\mathrm{P} 1 \neq \mathrm{P} 3$ and $\mathrm{P} 2 \neq \mathrm{P} 3$ \\
It was interesting & 3,49 & 3,81 & 3,78 & None \\
I enjoyed it & 3,55 & 3,92 & 3,73 & $\mathrm{P} 1 \neq \mathrm{P} 2$ \\
It was quick & 5,19 & 5,20 & 4,09 & $\mathrm{P} 1 \neq \mathrm{P} 3$ and $\mathrm{P} 2 \neq \mathrm{P} 3$
\end{tabular}

Table II.

Respondents' evaluations for the three tested protocols 


\section{Evocative richness}

Comparing the evocative richness of such different protocols is very challenging. As richness may also be related to the nature of the indicated favourite brands, we decided to compare the insights produced by the three protocols mainly for the two most frequently chosen brands, specifically Apple and Ikea, and to have them assessed through their results' summaries by a group of experts.

\section{First protocol: emotional attachment scale}

In total, 10 per cent of the evaluations state that the proposed scales poorly describe the emotions. That figure increases to 24 per cent if we take the precedent grade (just before "describes poorly"). From a traditional Likert scale's protocol, we can clearly compare the level of emotions elicited by the two brands. Generally, Apple is rated emotionally higher than Ikea. For Apple, the level of connection is specifically strong (5.58 out of 7). However, Ikea is considered more friendly and peaceful than Apple (Figure 2).

\section{Second protocol: online multi-image elicitation}

As an outcome of the analyses performed within the OMIE protocol (Ganassali, 2016), brands, selected pictures and textual justifications[3] can be represented together on a factorial map so that associations may appear. In our example, it is quite clear that Apple is associated with emotions such as not only surprise, impressiveness or sharing but also relaxation. In those results, Ikea relates to conviviality, joy, happiness and friendship. The other plotted elements on the factorial map may help to possibly identify the major dimensions differentiating brand-related emotional responses in our study: sophistication/ distance on the left versus ordinariness/familiarity on the right of the horizontal axis; collective pleasure on the bottom versus individual care on the top of the vertical axis.

\section{Third protocol: online collage with uploaded pictures}

Based on approximately 20 respondents per brand, from Figure 5, we can analyse the uploaded pictures for the two brands in a systematic way. Three topics are coded by a

\begin{tabular}{|l|l|l|}
\hline & Apple & Ikea \\
\hline Affectionate & 4.05 & 2.94 \\
\hline Friendly & 2.65 & 3.63 \\
\hline Loved & 2.70 & 2.00 \\
\hline Peaceful & 2.82 & 4.41 \\
\hline Passionate & 3.91 & 2.35 \\
\hline Delighted & 4.67 & 3.71 \\
\hline Captivated & 4.83 & 4.00 \\
\hline Connected & 5.58 & 3.94 \\
\hline Bonded & 4.36 & 3.75 \\
\hline Attached & 4.86 & 4.50 \\
\hline
\end{tabular}

What is the extent to which the following words describe your feelings toward your favourite brand?

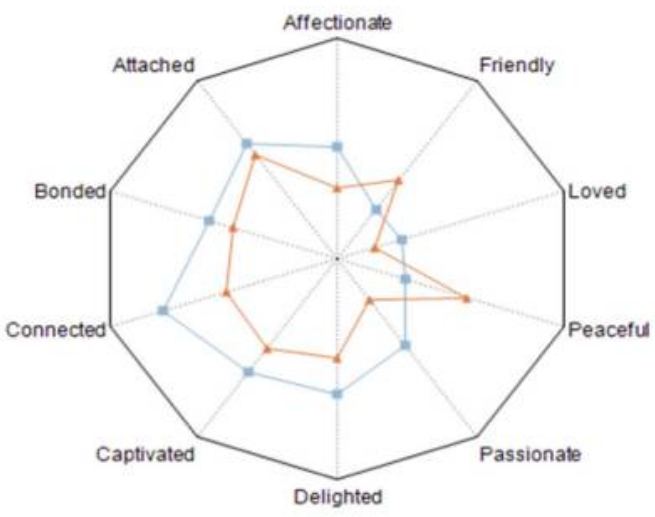

Figure 2. Emotional differences between Apple and Ikea captured by Protocol 1 
procedure of content analysis (Bell, 2004): colours, genders and of course leading emotions. As shown in Table III, we can clearly see that evocations are quite different for the two brands. Apple is black and white (and a little grey too), whereas Ikea is whiter and more multicolour. Additionally, Ikea is more feminine. As far as emotions and feelings are concerned, our coding shows that the associations for the two brands are efficiency, polyvalence and touch for Apple, with some aspects of innovation, simplicity and aesthetics; for Ikea, mainly a profusion of colours and aesthetics, with some minor dimensions of sharing, creativity/inspiration, joy and comfort.

\section{Evaluation of insights through results' summaries}

As a final stage of our work, we conducted an experiment to derive a coherent assessment of the insights produced by the results of our three protocols. As a first step, we asked international postgraduate students to write summaries of results on the basis of the outcomes of the three protocols (Figures 3, 4 and 5). Two groups of three or four individuals were randomly assigned to one of the three cases and were asked to write a short summary (half to one page) formulating some comments and conclusions to describe the emotions consumers feel towards Apple and Ikea. Each group was given one hour to perform the task. As a second step, coordinators of the two groups assigned to the same protocol were asked to put their works together so that we could have one summary per protocol in the end. The third step was an online survey[4] in which we asked experts to evaluate those three summaries in the way they would be useful and relevant for Apple and Ikea marketing managers to properly capture and understand the emotions that consumers associate with their brands. They were required to read and rate two summaries of results (randomly assigned to them among the three), on a list of six criteria designed to assess the depth and relevance of insights. They also had to choose the best one from the perspective of Apple and Ikea marketing managers. We also collected 62 expert evaluations from 19 different countries (mainly France, Poland and Germany). Of this group of experts, 60 per cent are academics in the field of marketing or more specifically brand management or marketing research and 40 per cent are research analysts or marketing managers. The group comprised 55 per cent of men and 45 per cent of women with a median age of 44 years.

As we can see from Figure 5, Protocol 2 (OMIE) gets the highest evaluations[5] on the six criteria we defined, and Protocol 1 was the lowest on five of the six criteria.

Based on the summaries chosen by our experts for being globally the best taking the perspective of Apple and Ikea's marketing managers, we can confirm that the visual protocols statistically give better results. OMIE is considered as the best in almost 70 per cent of the situations versus almost 55 per cent for the on-line collage. The scale is only chosen in 28 per cent of the cases (Table IV).

\section{Table III.}

Certain content analysis outcomes of the uploaded pictures

\begin{tabular}{ll}
\hline Protocols & Apple \\
\hline Colours $(n>3)$ & $\begin{array}{l}\text { White (18) and Black (17), Grey (9), Blue } \\
\text { (6), Red (5) and Yellow (4) }\end{array}$ \\
Gender $(n>3)$ & Male (8) and Female (6) \\
Dominant & $\begin{array}{l}\text { Efficiency/reliability (8), Touch (5) } \\
\text { emotions or }\end{array}$ \\
feelings $(n>2)$ & (3) and Aesthetics/design (3)
\end{tabular}

Ikea

White (21), Multicolour (10), Grey (10), Blue (10), Brown (10) and Black (4)

Female (9)

Multicolour (10), Aesthetics/design (9),

Profusion (7), Sharing (6), Creativity/

inspiration (6), Joy (5) and Comfort (4) 
Figure 3. Emotions captured by Protocol 2 (OMIE): results of correspondence analysis

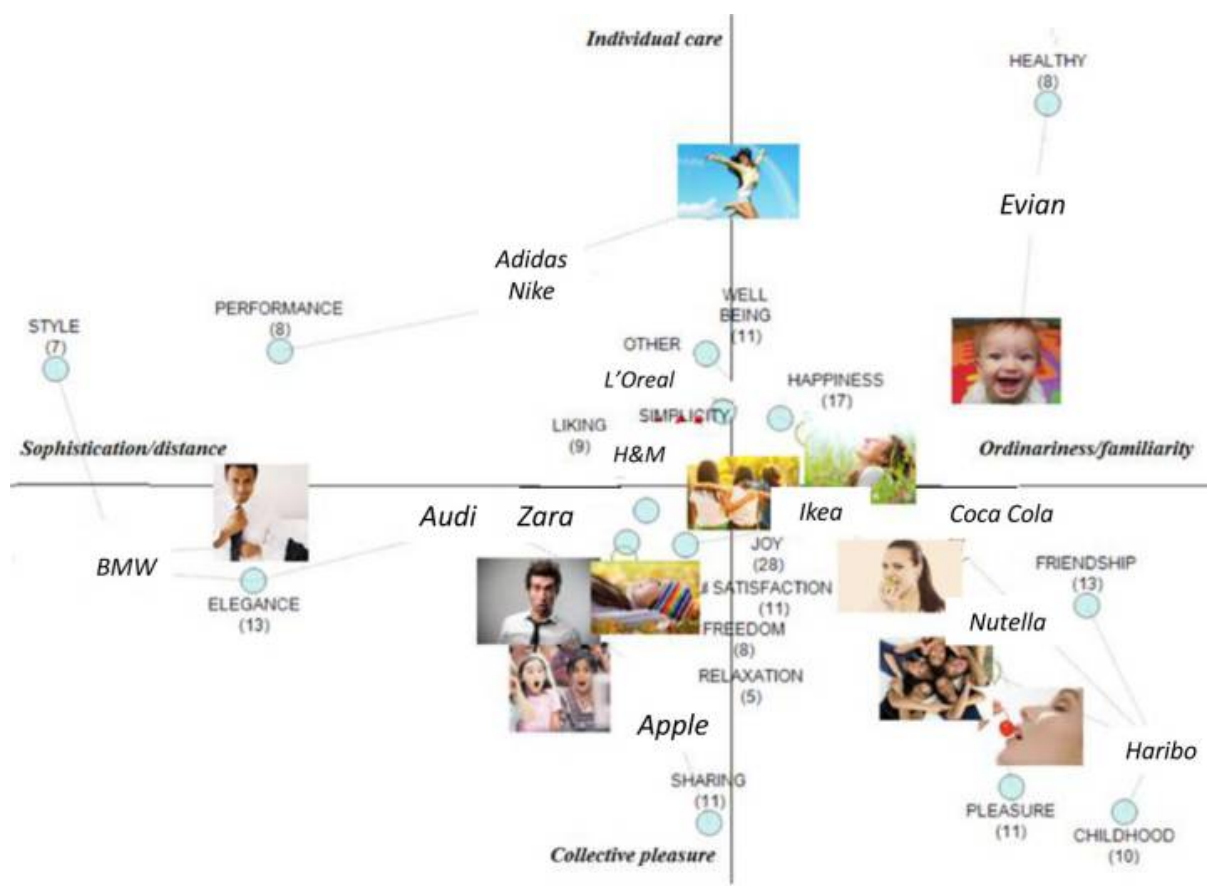

\section{Conclusions}

This study contributes to existing literature through advancing our understanding of the potential use of visual and spontaneous mixed protocols for consumer behaviour research. For exploratory purposes, our results suggest that those techniques are able to generate deeper insights than only using a closed group of scales.

As they do not follow exactly the same methodological objective, it is not surprising to see that the three protocols provide researchers with different levels of quality and different types of insights. Regarding the depth of the insights, the Likert scales are very standardised and therefore easy to analyse for comparing consumers' perceptions about different brands. However, the quality of the insights is strongly related to the accuracy of the tool for capturing the studied phenomenon. In the case of emotions, it remains quite challenging to find the right instrument able to capture a wide variety of emotions. In our example, the emotional attachment scale (Thomson et al., 2005) first shows that one brand ranks globally higher than the other in terms of global emotional intensity. It specifies the dimensions on which the "competing" brands are better: connection for Apple, friendliness and peacefulness for Ikea in our case. It is also difficult to ensure that some important brand emotions are not missing because they could not be properly captured by the standardised instrument used. Like all positivist tools (Mukherji and Albon, 2014), those types of scales may lack in accuracy and may produce superficial information. In particular, for emotions, it is admitted (Paivio, 1971) that their verbalisation is not always easy or possible. Our respondents rate the scale protocol quite low in terms of expressiveness. In addition to that, 40 per cent of consumers are choosing only three points or fewer within the whole set of seven modalities. In the lists of scale 
Figure 4.

Pictures uploaded to express feelings towards Apple (back) and Ikea (front)

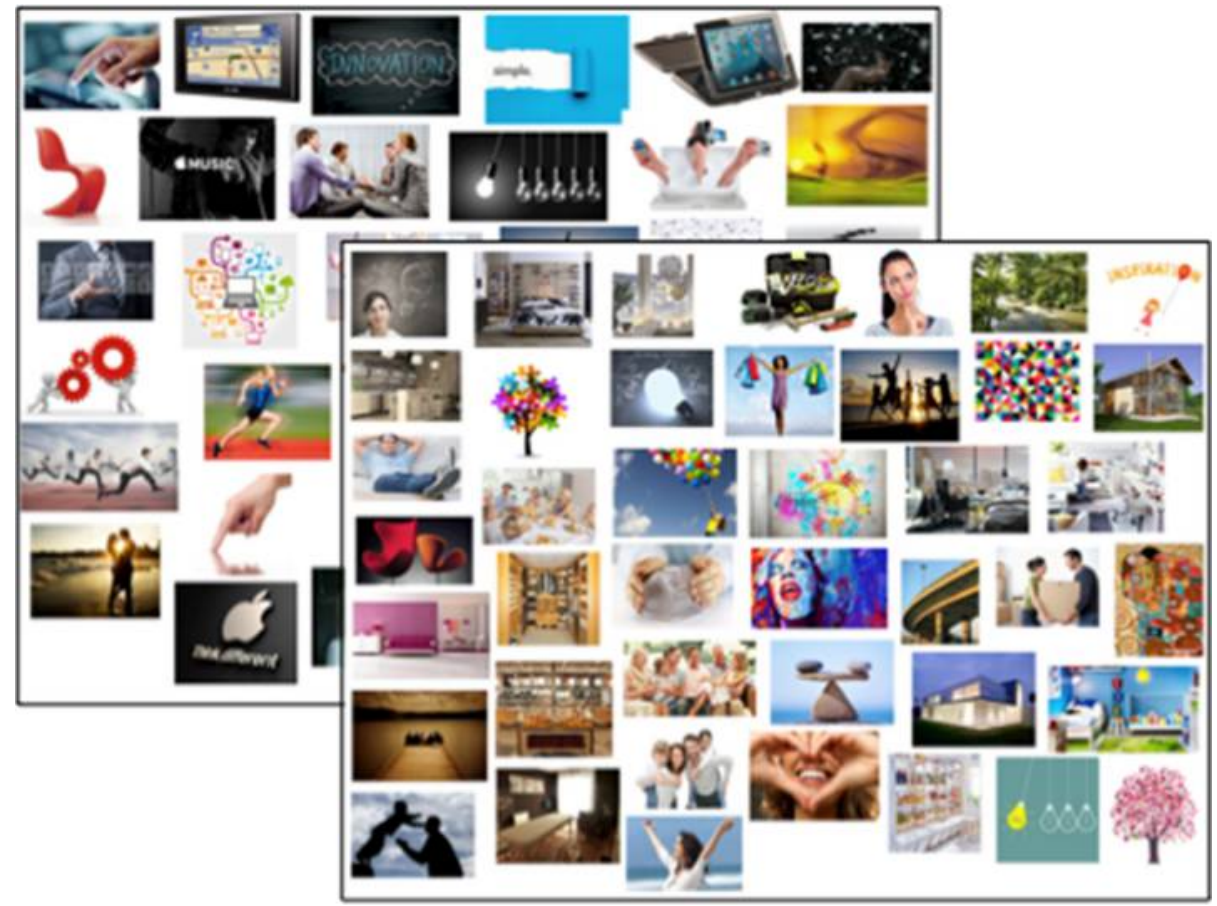

Figure 5. Assessment of the three protocols by experts - mean values

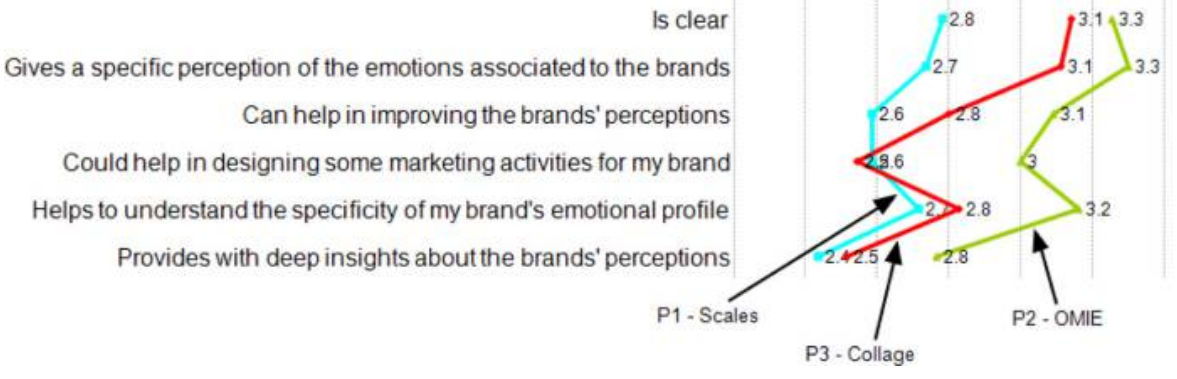

Table IV.

Success rates for the three protocols

\begin{tabular}{lccc}
\hline Protocols & No. of evals & No. of bests & \% of success \\
\hline P1 Scales & 46 & 13 & 28,3 \\
P2 OMIE & 43 & 30 & $69,8(*)$ \\
P3 Online & 35 & 19 & $54,3(*)$
\end{tabular}

Note: $(*)$ P2 and P3 percentages are significantly different from P1, at $p=0.05$ ( $t$ test 
questions, the respondents sometimes tend only to choose a very narrow range of responses from all the possibilities. This behaviour pattern referred to as "nondifferentiation" where respondents satisfice shows a lack of interest and a weak level of effort for responding (Ray and Muller, 2004).

In terms of memorisation, according to the dual coding theory, it has been recognized that the verbal system is activated when verbal stimuli are present. It dominates in the case of tasks that require verbal, more rational responses, whereas the non-verbal system is activated when non-verbal stimuli are present and dominates in the case of tasks that require non-verbal, more affective responses (Paivio, 1971). It was recently demonstrated (Herz and Diamantopoulos, 2013, p. 111) in a mixed study of country-specific associations that visual methods (collages in this case) perform better when it comes to detecting consumption-related affective associations. The authors point out that "the adoption of both verbal- and nonverbal-based approaches provides complementary insights on consumer brand associations". This provides confirmation that mixed visual protocols such as OMIE would be highly relevant for research where the affective dimension is important. Recently, the use of images as a means of expressing emotional reactions was discussed and validated in a study by Yoon et al. (2013). The authors used images to facilitate "affective granularity" that is a more refined and in-depth expression of affective responses. Derbaix and Pham (1989) proposed a classification of affects with seven categories: appreciation (the most cognitive of all reactions), attitude, preference, temperament, humour, sentiment and shock (the most affective). One can therefore say that techniques like OMIE are particularly useful for detecting the most intense affects such as humour, sentiments or even strong experiences, which verbal accounts cannot always accurately render (Derbaix and Pham, 1989).

This is mainly why visual protocols may be specifically promising: they are considered generally as useful for "capturing deep contextual meanings of consumer experience" (Rohani, Aung and Rohani, 2014). We have tested two of them and they clearly seem to provide researchers with deeper insights, in particular a better emotional granularity (Yoon et al., 2013). The respondents definitively rate those visual instruments as more interesting, enjoyable and expressive. The online-collage - as a very spontaneous instrument - provides researchers with more specific emotional responses. For example, the multicolour feeling associated with Ikea cannot be easily elicited through pre-defined scales of emotional attributes. However, as shown in our experiment, that protocol may increase significantly the number of dropouts because it may be perceived sometimes as difficult and demanding, even if in the end, a 20 per cent dropout rate is not that high for such a task. If we look at the respondents' evaluations, the OMIE seems to be a good compromise between convenience and expressiveness. Looking at the insights we obtained from the responses, they are more specific than the Likert scales' dimensions, but clearly, less rich than the ones obtained by the online collage. However, the quality of data, the respondents' assessment and the experts' insights evaluation are higher with OMIE.

More than promoting one protocol instead of another, we may learn from our experiment that those different emotional self-report measurements can be adapted to certain diverse research situations. Likert scales are useful for very confirmatory or comparative analyses, when researchers are clear about the nature of the emotions they want to assess. In that case, for example, they may resort to the related instruments like the ones specifically developed for brand love (Albert et al., 2008) or brand trust (Delgado-Ballester et al., 2003). For a more exploratory approach, the online collage may be well adapted. In fact, as a spontaneous, open and projective protocol disseminated in large scale through the internet, that 
instrument is likely able to identify more precisely the various dimensions of the emotional relationship between consumers and their favourite brands. The combination of visual and textual responses provides researchers with a wide set of complementary information which they naturally have to interpret and recode cautiously. The same applies for the OMIE. As the respondent is proposed a selection of 20 to 30 pictures, that instrument is less open than the collage. However, the textual justifications in the second stage of the protocol may also elicit more specific and precise emotional states.

The results of our study lead us to question the systematic use of Likert scales to assess or capture consumers' emotional responses to brands regardless of the situation. Essentially, we do not have to really consider the three protocols we assessed as competitive ways to collect data. We could actually recognise that they could help CBR researchers in various research situations. Online collage is certainly the most adapted to a very exploratory context, when the nature of the CBR is to be discovered. Likert scales are adapted to a confirmatory approach, when the characteristics of the relationship are already well-known, and when researchers want, for example, to compare the level of that sentiment across various profiles of consumers or correlate it with some other concepts. The OMIE seems to be suitable to some intermediate situations, when the CBR is estimated, but should be specified in a more refined way. Additionally, OMIE mixes different types of measurements (Ganassali, 2016): selection of pictures, textual justifications of choice and possibly, traditional scales for complementary evaluations, which lead to triangulation opportunities. As we can see, the range of possible effective methods for measuring consumers' responses towards brands is finally quite wide but it seems like CBR researchers do not yet use it enough.

In many social science surveys - and particularly in marketing - the researcher or research analyst expects active (and even "productive") participation from the subjects solicited. They hope for their involvement and commitment so as to obtain sufficient breadth and depth of expression in their "insights", which are supposed to be useful when making decisions in the future. In this respect, mixed visual protocols like OMIE online collages are promising when it comes to stimulating the abundance and diversity of responses. Such approaches now offer many opportunities for research questions relating to experiential consumption, advertising persuasion or the detection and evaluation of the emotional (Albert et al., 2008) or symbolic values of a brand. This is particularly relevant for certain areas such as tourism, leisure activities, culture, luxury products, hygiene and beauty products, where it is sometimes difficult to express brand attributes verbally. From a managerial perspective, those visual mixed techniques are some concrete examples of the twofold quali-quant approach through which practitioners are generally convinced (Macer et al., 2007). Furthermore, it represents excellent value for money as it generates a large volume of insights that are relatively rich and objective for relatively low implementation costs. Finally, this type of visual protocol carries good aesthetic appeal, thus contributing to a more modern and enhancing image of the focal organisation, which is not a negligible advantage when the research targets customers or staff performance.

As a future research, we could try to identify whether there are some specific profiles of consumers who would be more sensitive or reactive to online visual protocols than others, for example, young people or technophiles. Perhaps there could be some cultural differences as well in the way we use pictures and words to express our feelings, and this could be investigated in the future within a larger intercultural study. 


\section{Notes}

1. We accessed a database of 520 international papers published from 1999 to the present - all related to consumer-brand relationship, used by Noël Albert for a forthcoming article. A lexical analysis of the full texts showed the following results: "scale" is quoted 1531 times in 260 articles (50 per cent of the papers), "item" is quoted 2128 times in 268 papers (52 per cent of the papers). "Picture" is quoted 357 times in 118 articles (26 per cent) and "open-ended question" (or equivalent) only three times in three articles (0.006 per cent of the papers).

2. The set of pictures proposed to the respondents is developed according to a procedure described by the authors. The images are selected by a group of researchers to cover all of the theoretical dimensions identified in the literature of the focal concept. The multi-image presentation is designed so that at least three images are related to each dimension. An inter-coder reliability test is recommended to verify that the right images have been associated with the different themes. For further details and examples, see Ganassali (2016).

3. Textual justifications were coded via lexical analysis (Bolden and Moscarola, 2000).

4. See www.sphinxonline.com/SurveyServer/s/etudiup/eval3prots/questionnaire.htm

5. $\mathrm{P} 2$ is higher than $\mathrm{P} 1$ for the five first criteria $-\mathrm{P} 3$ is different from $\mathrm{P} 1$ for criteria 1 and $2-\mathrm{P} 2$ is higher than P3 for criterion 4 - $t$ test statistically significant at $p=0.05$

\section{References}

Albert, N., Merunka, D. and Valette-Florence, P. (2008), "When consumers love their brands: exploring the concept and its dimensions", Lournal of Business Research, Vol. 61 No. 10, pp. 1062-1075.

Anastas, M. (1994), "Visuals stimulate richer response in focus groups and individuals inter-views", Quirk's Marketing Research Review, Vol. 8 No. 10, pp. 38-39.

Baptiste, A., Belisle, C., Péchenart, J.M. and Vacheret, C. (1991), Photolangage. Une méthode Pour Communiquer en Groupe par la Photo, les Editions Organisation, Paris.

Bell, P. (2004), "Content analysis of visual images", in Van Leeuwen, T. and Jewitt, C. (Eds), The Handbook of Visual Analvsis, Sage Publications Ltd, London.

Bolden, R. and Moscarola, J. (2000), "Bridging the quantitative-qualitative divide: the lexical approach to textual data analysis", Social Science Computer Review, Vol. 18 No. 4, pp. 450-460.

Bradley, M. and Lang, P. (1994), "Measuring emotion: the self-assessment manikin and the semantic differential”, Lournal of Behavioral Therapy \& Experimental Psychiatry, Vol. 25 No. 1, pp. 49-59.

Delgado-Ballester, E., Munuera-Alemán, J.L. and Yagüe-Guillén, M.J. (2003), "Development and validation of a brand trust scale", International Iournal of Market Research, Vol. 45 No. 1 , pp. 35-53.

Derbaix, C. and Filser, M. (2011), L'affectif dans les Comportements d'achat et de Consummation, Economica, Paris.

Derbaix, C. and Pham, M.T. (1989), "Pour un développement des mesures de l'affectif en marketing: synthèse des prérequis", Recherche et Applications en Marketing, Vol. 4 No. 4, pp. 71-87.

Derbaix, C. and Pham, M. (1991), "Affective reactions to consumption situations: a pilot investigation", Iournal of Economic Psychology, Vol. 12 No. 2, pp. 325-355.

Derbaix, C. and Poncin, I. (2005), "La mesure des réactions affectives en marketing: évaluation des principaux outils”, Recherche et Applications en Marketing, Vol. 20 No. 2, pp. 55-75.

Droulers, O. and Lajante, M. (2015), “Apports de la psychophysiologie à l'étude des émotions en marketing", in Poncin, I. and Herrmann, J.L. (Eds), Les réactions Affectives $d u$ Consommateur: ces Raisons du cóur que la Raison Ignore, Presses Universitaires de Louvain, Louvain. 
Ekman, P., Freisen, W.V. and Ancoli, S. (1980), "Facial signs of emotional experience", Lournal of Personality and Social Psychology, Vol. 39 No. 6, pp. 1125-1134.

Förster, K. (2014), "Do emotions pay off? Effects of media Brand emotions on cognitive relief, identification and prestige", Online Journal of Communication and Media Technologies, Vol. 4 No. 4, pp. 34-57.

Ganassali, S. (2008), "The influence of the design of web survey questionnaires on the quality of responses", Survey Research Methods, Vol. 2 No. 1, pp. 21-32.

Ganassali, S. (2016), "Le mur d'images en ligne: présentation et apports d'un protocole hybride", Recherche Et Applications en Marketing, Vol. 31 No. 4, pp. 70-88.

Gil, S. (2009), "Comment étudier les émotions en laboratoire?", Revue Électronique De Psychologie Sociale, Vol. 4, pp. 15-24.

Harper, D. (2002), “Talking about pictures: a case for photo elicitation”, Visual Studies, Vol. 17 No. 1, pp. 13-26.

Herz, M.F. and Diamantopoulos, A. (2013), "Country-specific associations made by consumers: a dualcoding theory perspective”, Journal of International Marketing, Vol. 21 No. 3, pp. 95-121.

Holbrook, M. and Hirschman, E. (1982), "The experiential aspects of consumption: consumer fantasies, feelings and fun", Lournal of Consumer Research, Vol. 9 No. 2, pp. 132-140.

Jansson, A. (2002), "The mediatization of consumption: towards an analytical framework of image culture", Journal of Consumer Culture, Vol. 2 No. 1, pp. 5-31.

Kaiser, S. and Wehrle, T. (2001), "Facial expressions as indicators of appraisal processes", in Scherer, K. R., Schorr, A. and Johnstone, T. (Eds), Appraisal Processes in Emotions: Theory, Methods, Research, Oxford University Press, New York, NY, pp. 285-300.

Kim, M.J., Cho, M.E. and Kim, J.T. (2015), "Measures of emotion in interaction for health smart home", International Iournal of Engineering and Technology, Vol. 7 No. 4, pp. 343-348.

Koller, M. and Sinitsa, E. (2009), "Mixed methods in online research - conceptualisation and future research agenda", Proceedings of the General Online Research, University of Vienna, Austria, 6th-8th April 2009, GOR.

Krosnick, J. (2000), "The threat of satisficing in surveys: the shortcuts respondents take in answering questions", Survey Methods Newsletter, Vol. 20, pp. 4-8.

Macer, T., Pearson, M. and Sebastiani, F. (2007), "Cracking the code: what customers say in their own words", Proceedings of the 50th Annual Conference of the Market Research Society (Brighton, UK, 22-23 March), The Market Research Society.

Mossholder, K., Settoon, R., Harris, S. and Armenakis, A. (1995), "Measuring emotion in open-ended survey responses: an application of textual data analysis)", Journal of Management, Vol. 21 No. 2, pp. 335-355.

Mukherji, P. and Albon, D. (2014), Research Methods in Early Childhood: An Introductory Guide, 2nd ed., Sage Publications.

Ng, M. and Hort, J. (2015), "Insights into measuring emotional response in sensory and consumer research", Rapid Sensory Profiling Techniques and Related Methods, Elsevier, pp. $71-90$.

Paivio, A. (1971), Imagery and Verbal Processes, Holt, Rinehart and Winston, New York, NY.

Pawle, J. and Delfaud, D. (2014), "How does your cappuccino feel?”, Research World, Vol. 2014 No. 44, pp. 50-52.

Pink, S. (2011), "Digital visual anthropology: potential and challenges", in Banks, M. and Ruby, J. (Eds ), Made to be Seen: Perspectives on the History of Visual Anthropology, University of Chicago Press, Chicago, IL, pp. 209-233.

Poels, K. and Dewitte, S. (2006), "How to capture the heart? Reviewing 20 years of emotion measurement in advertising", Journal of Advertising Research, Vol. 46 No. 1, pp. 18-37. 
Ray, D. and Muller, C. (2004), "Des limites de l'échelle 1-10: Caractérisation des sous-échelles utilisées par les répondants", in Ardilly, P. (Ed.), Echantillonnage et méthodes d'enquête, Dunod, Paris.

Rohani, L.S., Aung, M. and Rohani, K. (2014), "One step closer to the field: visual methods in marketing and consumer research", Qualitative Market Research: An International Journal, Vol. 17 No. 4, pp. 300-318.

Scott, L.M. and Vargas, P. (2007), "Writing with pictures: toward a unifying theory of consumer response to images", Lournal of Consumer Research, Vol. 34 No. 3, pp. 341-356.

Scott, L. (1994), "Images in advertising: the need for a theory of visual rhetoric", Lournal of Consumer Research, Vol. 21 No. 2, pp. 252-273.

Spanjaard, D., Young, L. and Freeman, L. (2014), "Emotions in supermarket brand choice: a multimethod approach", Qualitative Market Research: An International Journal, Vol. 17 No. 3, pp. 209-224.

Tashakkori, A. and Teddlie, h. (2010), Handbook of Mixed Methods in Social \& Behavioral Research, Sage Publications, Thousand Oaks, CA.

Thomson, M., MacInnis, D. and Park, C.W. (2005), "The ties that bind: measuring the strength of consumers' emotional attachments to brands", Journal of Consumer Psychology, Vol. 15 No. 1, pp. $77-91$.

Vernette, E. (2007), “Une nouvelle méthode pour interpréter le sens d’une expérience de consommation: l'Album on line (AOL)", Actes de la 12ème Journée de recherche en Marketing de Bourgogne, pp. 37-55.

Warren, S. (2002), "Show me how it feels to work here: using photography to research organizational aesthetics", Ephemera - Critical Dialogues on Organization, Vol. 2 No. 3, pp. 224-245.

Wilson, E., Bengtsson, A. and Curran, C. (2014), "Brand meaning gaps and dynamics: theory, research, and practice”, Qualitative Market Research: An International Journal, Vol. 17 No. 2, pp. 128-150.

Yoon, J.K., Desmet, P. and Pohlmeyer, A. (2013), "Embodied typology of positive emotions: the development of a tool to facilitate emotional granularity in design", Proceedings of 5th International Congress of International Association of Societies of Design Research, pp. 1195-1206.

Zaltman, G. (1997), "Rethinking marketing research: putting people back in”, Lournal of Marketing Research, Vol. 34 No. 4, pp. 424-437.

Zaltman, G. and Coulter, R.H. (1995), "Seeing the voice of the customer: metaphor-based advertising research", Journal of Advertising Research, Vol. 35 No. 4, pp. 35-51.

\section{Corresponding author}

Stéphane Ganassali can be contacted at: sgana@univ-smb.fr 